\title{
Impacto de alterações nas exportações de açúcar e álcool nas regióes Centro-Sul e Norte-Nordeste sobre a economia do Brasil ${ }^{1}$
}

\author{
Cinthia Cabral da Costa* \\ Heloisa Lee Burnquist** \\ Joaquim José Martins Guilhoto***
}

Resumo: Este trabalho teve por objetivo estimar o impacto de um aumento nas exportações brasileiras de açúcar e de álcool sobre os níveis de produção e de emprego do país. Para tal, utilizou-se uma matriz de insumo-produto inter-regional da economia brasileira. Verificou-se, a princípio, que um choque de demanda, resultante de uma expansão das exportações de açúcar, apresenta um maior impacto sobre o produto e o emprego do país, comparado ao derivado de um incremento nas exportações de álcool. A análise regional mostrou ainda que o impacto de um choque de demanda - seja esse resultado de uma expansão de exportações de açúcar ou de álcool - sobre a produção e emprego na região Norte-Nordeste, é mais expressivo que na região Centro-Sul. Esses resultados são importantes para subsidiar a identificação de políticas e o estabelecimento de metas para incentivar um produto ou região, considerando-se a propagação dos benefícios econômicos.

Palavras-chave: exportação, açúcar, álcool, Brasil, matriz insumo-produto.

* Pesquisadora do Instituto de Estudos do Comércio e Negociações Internacionais - ICONE; Professora licenciada da Faculdade de Estudos Administrativos - FEAD. costa-cinthia@uol.com.br

**Profa. Dra. do Departamento de Economia, Administração e Sociologia da ESALQ/ USP. hlburnqu@carpa.ciagri.usp.br

***Prof. Dr. do Departamento de Economia da USP. guilhoto@usp.br

${ }^{1}$ Este trabalho apresenta-se como parte da tese de doutorado da seguinte autora: Cinthia Cabral da Costa. 
Classificação JEL: F16; C67

\begin{abstract}
This paper estimates the impact of an increase in Brazilian sugar and ethanol demand for exports upon the countries' overall production and employment. The impacts were simulated considering each of the major cane producing areas of the country (Center-South and North-Northeast). An inter-regional input-output matrix for the Brazilian economy was used for that purpose. It was observed that a demand shock, resulting from an expansion of sugar exports presented an impact of greater magnitude upon the countries' production and employment when compared to the impact from an increase in ethanol. In addition, the results indicated that when the impact is generated at the North-Northeastern Brazil, production and employment is more affected than when it begins at the Center-South region of the country. The result of how the economic benefits are propagated, is important to identify policies and establish targets for regional production.
\end{abstract}

Key words: export, sugar, ethanol, Brazil, input output matrix.

JEL Classification: F16; C67

\title{
1. Introdução
}

Na segunda metade da década de 1990, além de assumir a posição de maior produtor e exportador mundial de açúcar, o Brasil tornou-se o maior produtor mundial de álcool combustível e de cana, detendo volumes expressivos do total global para cada um desses bens. Nesse contexto, a expansão do mercado internacional, no caso do açúcar, e a consolidação de um mercado internacional, no caso do álcool, tornaram-se aspectos essenciais para a evolução equilibrada do setor sucroalcooleiro brasileiro.

Em função de seus baixos custos de produção de açúcar e álcool, o Brasil tem condições de ocupar uma posição de maior destaque nestes mercados. Visando reduzir o elevado grau de protecionismo que vem sendo mantido, por décadas, no mercado internacional de açúcar, as ne- 
gociações no âmbito da Organização Mundial do Comércio (OMC), passaram a ser conduzidas com maior empenho pelos países exportadores desta commodity. No que tange ao álcool, a assinatura do Protocolo de Kyoto parece ter sido um fator essencial para efetivar a implementação de um mercado internacional de álcool, o que, até poucos anos atrás, parecia ser uma possibilidade bastante remota. Assim, é importante que se avaliem os efeitos que um aumento na demanda externa por esses produtos pode vir a ter na economia nacional, particularmente no que tange à produção e ao emprego agregado.

Um outro aspecto interessante pesquisado neste trabalho é se o impacto de um choque de demanda, resultante do aumento nas exportações de açúcar e álcool, apresenta-se diferenciado sobre a produção e o emprego das grandes regiões canavieiras do país: o Centro-Sul e Norte-Nordeste ${ }^{2}$. A princípio, espera-se que esse efeito possa ser diferente entre as regiões, particularmente em função de suas distinções quanto aos sistemas produtivos prevalecentes, à tecnologia empregada, e às condições econômicas.

Resumindo-se, portanto, este trabalho teve como objetivo obter estimativas dos valores de possíveis aumentos das exportações brasileiras de açúcar e álcool, resultantes dos choques de mudanças no mercado internacional destes produtos, sobre os níveis de produção e de emprego, considerando-se, separadamente, a região Centro-Sul e a região Norte-Nordeste do Brasil.

\section{Metodologia}

Os efeitos sobre a produção e emprego foram simulados, pressupondo-se que inicialmente ocorre um aumento de R $\$ 1$ milhão na demanda final por açúcar e por álcool, respectivamente em cada grande região, separadamente. Para obter as estimativas referidas acima, considerase que um incremento na demanda estrangeira pelo produto nacional afeta, por sua vez, a demanda nacional pelos produtos açúcar e álcool,

${ }^{2}$ A região Centro-Sul é definida agregando-se os estados das regiões Centro-Oeste, Sul e Sudeste do Brasil: Minas Gerais, São Paulo, Rio de Janeiro, Espírito Santo, Paraná, Santa Catarina, Rio Grande do Sul, Mato Grosso, Mato Grosso do Sul e Goiás. A região Norte-Nordeste compreende os estados: Alagoas, Pernambuco, Sergipe, Paraíba, Maranhão, Piauí, Bahia, Tocantins, Rio Grande do Norte, Pará, Amapá, Rondônia, Roraima e Amazonas. 
respectivamente. Isso, por sua vez, altera o nível de produção e emprego agregados da economia, apresentando efeitos que podem ser avaliados tanto sob um âmbito regional como nacional, conforme descrito em Miller \& Blair (1985). Os efeitos são estimados considerando-se uma matriz de insumo-produto inter-regional das regiões Centro-Sul e NorteNordeste do Brasil, estimada para o ano de 1999, por Guilhoto³.

\subsection{Simulação de impacto sobre a produção}

Para avaliar a magnitude relativa de um aumento simulado na demanda final por exportação de açúcar e álcool, sobre o nível de produção da economia brasileira, calcularam-se impactos diretos, indiretos e “induzidos pelo aumento de renda das famílias".

Para as análises inter-regionais empregaram-se coeficientes de insumos intra-regionais (dentro de uma região específica), e inter-regionais (entre as duas regiões). Os fluxos inter-regionais de comércio são considerados apenas no contexto de cada região, obtendo-se uma análise mais precisa dos fluxos existentes na economia brasileira.

\subsection{Geração de emprego}

A metodologia empregada para a análise dos fatores geradores de emprego é semelhante à utilizada anteriormente por Najberg \& Ikeda (1999). Em sua análise, esses autores consideraram três maneiras diferentes pelas quais são gerados os empregos de uma dada economia: (i) o emprego gerado diretamente (que representa o incremento no número de empregos para o setor que foi impactado); (ii) o emprego gerado de maneira indireta (que representa o número de empregos gerados em setores vinculados à indústria de açúcar e álcool, como, por exemplo, o setor de cana-de-açúcar); e, (iii) o emprego gerado por meio de um efeito-renda (pressupondo que o incremento na demanda agregada resulta em aumento de renda que possibilita o aumento na produção, particularmente de bens com elevada elasticidade renda da demanda, como é o caso, por exemplo, de alguns bens alimentares, como iogurtes etc.).

${ }^{3}$ GUILHOTO, J.J.M. (USP. FEA. Departamento de Economia, São Paulo). Comunicação pessoal, 2003. 
O procedimento empregado consiste em associar a matriz inversa de Leontief aos coeficientes de emprego dos setores da economia, que fornecem o número de empregos gerados direta e indiretamente, mediante uma variação na demanda final. Como foram analisadas matrizes inter-regionais, os multiplicadores de produção e de emprego estimados incluem não apenas os níveis de produção e emprego gerados na região em que foi dado o choque, como também os gerados nas demais regiões consideradas.

\subsection{Matriz de insumo-produto}

Ao contrário do que se observa na matriz insumo-produto divulgada oficialmente pelo Instituto Brasileiro de Geografia e Estatística (IBGE), a matriz empregada para o presente estudo, considera os setores enfocados pelo estudo, de forma mais desagregada, enquanto praticamente todos os outros são trabalhados de maneira mais agregada, ou de forma semelhante (Ver Quadro 1 do Anexo 1). Os setores que sofreram o choque de aumento nas exportações, foram o da fabricação de açúcar e o de álcool (setores 14 e 9, respectivamente, na matriz insumo-produto utilizada).

\section{Resultados e Discussão}

Os resultados apresentados neste item referem-se a um aumento de R\$ 1 milhão nas exportações de açúcar e de álcool, respectivamente, para cada uma das regiões analisadas, com a finalidade de identificar a sensibilidade das exportações de cada região para a economia brasileira.

\subsection{Impactos de um choque sobre demanda de açúcar e álcool sobre o nível de produção inter-regional e intra-regional}

Inicialmente calcularam-se os impactos na produção da economia brasileira em função de um choque de $\mathrm{R} \$ 1$ milhão sobre as exportações de açúcar. A Tabela 1 mostra o impacto na produção das regiões CentroSul e Norte-Nordeste. 

sobre a economia do Brasil

Tabela 1. Variações nos níveis de produção dos setores da economia do Norte-Nordeste (NNE) e do Centro-Sul (CS), em R \$ mil, resultantes do impacto direto, indireto e induzido pelo efeito renda de um aumento de R 1 milhão na demanda final de açúcar nessas duas regiões

\begin{tabular}{|c|c|c|c|c|c|}
\hline & \multirow[b]{2}{*}{ Setores } & \multicolumn{2}{|c|}{$\begin{array}{c}\text { Impacto na economia } \\
\text { do NNE }\end{array}$} & \multicolumn{2}{|c|}{$\begin{array}{c}\text { Impacto na economia } \\
\text { do CS }\end{array}$} \\
\hline & & $\begin{array}{r}\text { Aumento } \\
\text { na demanda } \\
\text { de açúcar } \\
\text { no NNE }\end{array}$ & $\begin{array}{r}\text { Aumento } \\
\text { na demanda } \\
\text { de açúcar } \\
\text { no CS }\end{array}$ & $\begin{array}{r}\text { Aumento na } \\
\text { demanda de } \\
\text { açúcar no } \\
\text { NNE }\end{array}$ & $\begin{array}{r}\text { Aumento } \\
\text { na demanda } \\
\text { de açúcar } \\
\text { no CS }\end{array}$ \\
\hline 1 & Cana-de-açúcar & 249,64 & 19,16 & 55,24 & 288,81 \\
\hline 2 & Restante Agropecuária & 109,50 & 18,29 & 72,41 & 80,86 \\
\hline 3 & Extrativa & 10,68 & 5,54 & 25,06 & 20,21 \\
\hline 4 & Metalurgia & 25,46 & 8,80 & 51,01 & 49,46 \\
\hline 5 & Mecânica & 15,98 & 3,05 & 50,62 & 58,46 \\
\hline 6 & $\begin{array}{l}\text { Material Elétrico e Ele- } \\
\text { trônico }\end{array}$ & 7,79 & 1,71 & 18,84 & 13,55 \\
\hline 7 & Material de Transporte & 3,43 & 0,90 & 38,67 & 21,52 \\
\hline 8 & $\begin{array}{l}\text { Madeira, Mobiliário, Ce- } \\
\text { lulose, Papel e Gráfica }\end{array}$ & 19,40 & 4,44 & 50,25 & 45,93 \\
\hline 9 & Álcool & 4,75 & 0,52 & 9,61 & 8,60 \\
\hline 10 & $\begin{array}{l}\text { Outros Elementos } \\
\text { Químicos não Petro- } \\
\text { químicos }\end{array}$ & 7,07 & 2,30 & 14,76 & 15,20 \\
\hline 11 & Refino do Petróleo & 52,66 & 15,69 & 105,07 & 96,38 \\
\hline 12 & $\begin{array}{l}\text { Produtos do Refino do } \\
\text { Petróleo }\end{array}$ & 46,29 & 13,29 & 68,15 & 57,94 \\
\hline 13 & $\begin{array}{l}\text { Têxtil, Vestuário e } \\
\text { Calçados }\end{array}$ & 50,48 & 10,00 & 58,91 & 73,26 \\
\hline 14 & Fabricação de Açúcar & 1172,63 & 1,47 & 14,65 & 1186,09 \\
\hline 15 & $\begin{array}{l}\text { Outros Produtos Alimen- } \\
\text { tares }\end{array}$ & 116,40 & 13,41 & 72,02 & 77,21 \\
\hline 16 & Indústrias Diversas & 10,88 & 2,05 & 31,44 & 27,47 \\
\hline 17 & SIUP & 99,33 & 8,26 & 39,47 & 89,74 \\
\hline 18 & Construção Civil & 13,12 & 1,00 & 4,74 & 13,70 \\
\hline 19 & $\begin{array}{l}\text { Serviços Prestados às } \\
\text { Famílias }\end{array}$ & 127,47 & 11,91 & 32,58 & 67,57 \\
\hline 20 & Outros Serviços & 611,55 & 54,88 & 277,31 & 511,53 \\
\hline
\end{tabular}

Fonte: resultados de pesquisa. 
Os resultados apresentados na Tabela 1 mostraram que os setores mais afetados pelo aumento na demanda final de açúcar na própria região que sofreu o choque foram: o setor 14 - fabricação de açúcar (impacto direto, indireto e induzido de R \$ 1,186 milhões no Centro-Sul e R \$ 1,173 milhões no Norte-Nordeste); o setor 1 - cana-de-açúcar (impacto direto, indireto e induzido de R $\$ 289$ mil no Centro-Sul e R \$ 250 mil no Norte-Nordeste) e o setor 20 - outros serviços (impacto direto, indireto e induzido de R $\$ 511$ mil no Centro-Sul e R \$ 611 mil no Norte-Nordeste). Conforme esperado, os impactos maiores refletem-se no próprio setor que sofreu o choque e no setor de cana-de-açúcar, por ser este último o maior fornecedor de insumos para o setor de açúcar. O setor de outros serviços da matriz insumo produto utilizada para o presente estudo agrega vários setores que são apresentados de maneira desagregados na matriz do IBGE. Acredita-se que isso explique, também, o valor elevado obtido para esse segmento da economia.

Observa-se ainda que, o aumento na demanda final de açúcar no Centro-Sul aumenta a produção dos setores do Norte-Nordeste em uma proporção menor do que o efeito de aumento de produção nos setores do Centro-Sul diante de um aumento de demanda final no açúcar do Norte-Nordeste (comparação das quarta e quinta colunas da Tabela 1). Considerando os impactos diretos, indiretos e induzidos pelo efeito renda, o aumento na demanda de açúcar em $\mathrm{R} \$ 1$ milhão no Centro-Sul aumenta em mais de $\mathrm{R} \$ 50$ mil apenas a produção do setor 20 - outros serviços, no Norte-Nordeste. Este mesmo aumento de demanda sobre a região Norte-Nordeste impõe um aumento na produção superior a $\mathrm{R} \$$ 50 mil, para diversos setores da região Centro-Sul.

A seguir, o impacto foi estimado considerando o mesmo choque de demanda para o setor de álcool. A Tabela 2 mostra o impacto do aumento de demanda de álcool nas regiões Norte-Nordeste e Centro-Sul. Observase que o impacto do choque em uma região sobre a mesma região considerada foi maior nos setores: 9 (álcool); setor 1 (cana-de-açúcar); e setor 20 (outros serviços). Verifica-se que os setores mais afetados pelo aumento de demanda de álcool, excetuando-se o próprio setor em que foi dado o choque (9), foram os mesmos setores mais afetados pelo aumento de demanda de açúcar. Observa-se também que esses impactos são maiores, mediante um aumento de demanda de açúcar, exceto para 

sobre a economia do Brasil

o caso do setor de cana-de-açúcar. Isto pode estar relacionado ao fato de se demandar mais cana-de-açúcar na produção de álcool do que de açúcar.

Tabela 2. Variações nos níveis de produção dos setores da economia do Norte-Nordeste (NNE) e do Centro-Sul (CS), em R\$ mil, resultantes do impacto direto, indireto e induzido pelo efeito renda, de aumento de R\$ 1 milhão na demanda final de álcool nestas regiões.

\begin{tabular}{|c|c|c|c|c|}
\hline \multirow[b]{2}{*}{ Setores } & \multicolumn{2}{|c|}{$\begin{array}{l}\text { Impacto na economia do } \\
\text { NNE }\end{array}$} & \multicolumn{2}{|c|}{$\begin{array}{l}\text { Impacto na economia } \\
\text { do CS }\end{array}$} \\
\hline & $\begin{array}{r}\text { Aumento na } \\
\text { demanda de } \\
\text { açúcar no } \\
\text { NNE }\end{array}$ & $\begin{array}{r}\text { Aumento } \\
\text { na demanda } \\
\text { de açúcar } \\
\text { no CS }\end{array}$ & $\begin{array}{c}\text { Aumento na } \\
\text { demanda de na } \\
\text { açúcar no } \\
\text { NNE }\end{array}$ & $\begin{array}{r}\text { Aumento } \\
\text { a demanda } \\
\text { de açúcar } \\
\text { no CS } \\
\end{array}$ \\
\hline 1 Cana-de-açúcar & 252,57 & 13,89 & 51,77 & 324,47 \\
\hline 2 Resto Agropecuária & 70,88 & 13,94 & 46,37 & 55,71 \\
\hline 3 Extrativa & 7,87 & 4,74 & 18,01 & 16,47 \\
\hline 4 Metalurgia & 11,95 & 4,77 & 25,66 & 23,48 \\
\hline 5 Mecânica & 7,81 & 1,31 & 24,34 & 30,81 \\
\hline 6 Material Elétrico e Eletrônico & 4,89 & 1,06 & 11,68 & 9,20 \\
\hline 7 Material de Transporte & 2,11 & 0,56 & 23,85 & 14,36 \\
\hline $\begin{array}{l}\text { Madeira, Mobiliário, } \\
\text { Celulose, Papel e Gráfica }\end{array}$ & 9,48 & 2,60 & 26,06 & 21,63 \\
\hline 9 Álcool & 1007,53 & 0,45 & 6,34 & 1011,01 \\
\hline $\begin{array}{l}10 \text { Outros Elementos Químicos } \\
\text { não Petroquímicos }\end{array}$ & 16,88 & 6,27 & 18,46 & 29,68 \\
\hline 11 Refino do Petróleo & 39,01 & 15,62 & 74,85 & 76,58 \\
\hline $\begin{array}{l}12 \text { Produtos do Refino do } \\
\text { Petróleo }\end{array}$ & 33,26 & 11,74 & 44,95 & 42,12 \\
\hline 13 Têxtil, Vestuário e Calçados & 16,38 & 2,97 & 21,43 & 18,50 \\
\hline 14 Fabricação de Açúcar & 52,08 & 8,91 & 14,50 & 62,18 \\
\hline 15 Outros Produtos Alimentares & 73,59 & 10,56 & 45,43 & 51,57 \\
\hline 16 Indústrias Diversas & 5,32 & 1,42 & 17,44 & 14,36 \\
\hline 17 SIUP & 84,09 & 10,51 & 26,80 & 80,55 \\
\hline 18 Construção Civil & 6,38 & 0,88 & 2,82 & 6,79 \\
\hline $\begin{array}{l}\text { Serviços Prestados às } \\
\text { Famílias }\end{array}$ & 78,94 & 9,55 & 19,97 & 42,62 \\
\hline 20 Outros Serviços & 373,92 & 46,36 & 174,16 & 322,23 \\
\hline
\end{tabular}


Observa-se ainda que, da mesma maneira que foi verificado em relação ao aumento de demanda de açúcar, o impacto inter-regional de um incremento na demanda de álcool, sobre a economia brasileira, foi maior mediante um choque originado na região Norte-Nordeste.

A Figura 1 procurou sintetizar os resultados obtidos nas Tabelas 1 e 2, e distingue também o impacto considerando os efeitos direto e indireto dos efeitos totais (direto, indireto e induzido), em relação ao nível de produção da economia brasileira. Observa-se, na Figura 1, que o impacto na demanda final de açúcar da região Norte-Nordeste pareceu afetar a produção, direta e indireta, da própria região, em $\mathrm{R} \$ 1,847$ milhão. No Centro-Sul, o impacto na própria região foi de R $\$ 2,162$ milhões. O impacto do efeito renda intra-regional, de um incremento de R 1 milhão na demanda de açúcar, mostrou-se, no entanto, bastante semelhante (R\$ 2,803 milhões no Centro-Sul e R \$ 2,754 milhões no Norte-Nordeste). Considerando os impactos inter-regionais, observou-se que o choque na demanda final de açúcar na região Norte-Nordeste causou um impacto na produção do Centro-Sul relativamente maior, da ordem de $\mathrm{R} \$ 1,09$ milhão. Portanto, o impacto total no valor da produção da economia brasileira apresenta-se maior quando o choque de demanda final de açúcar ocorre na região Norte-Nordeste, que foi estimado em $\mathrm{R} \$ 2,93$ milhões.

Figura 1 - Impactos na produção anual da economia das regiões Centro-Sul e Norte-Nordeste do Brasil, em relação ao aumento de demanda final de açúcar e de álcool no valor de R 1 milhão, nas regiões Centro-Sul e Norte-Nordeste

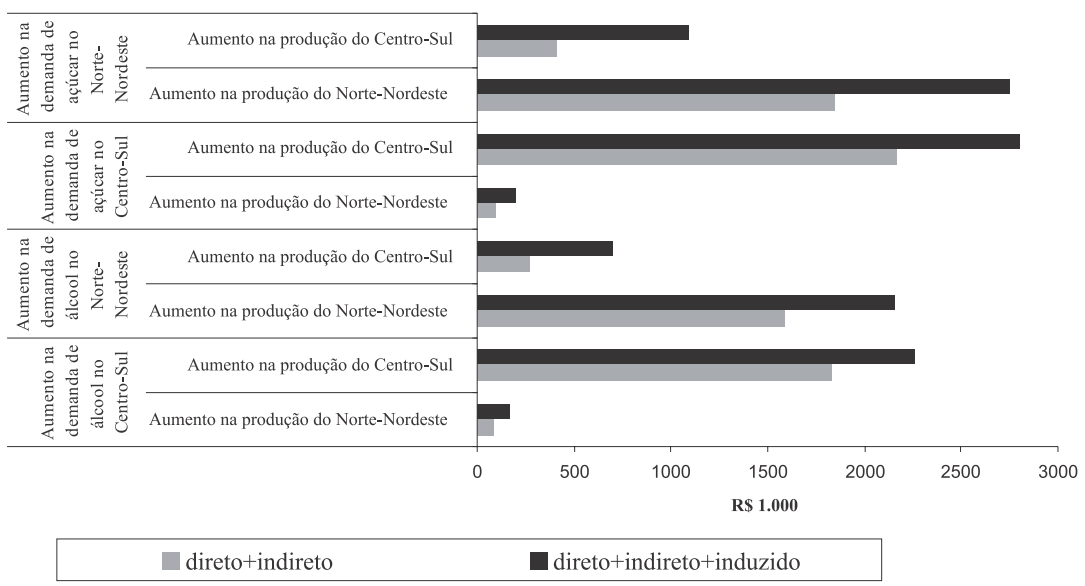

Fonte: resultados de pesquisa. 
Nota: o efeito induzido corresponde ao aumento da produção em função do aumento do efeito renda das famílias.

Acredita-se que esse maior impacto inter-regional do aumento de demanda de açúcar na região Norte-Nordeste sobre a economia do Centro-Sul ocorreu porque o Norte-Nordeste utiliza relativamente mais insumos produzidos no Centro-Sul, que o inverso, para todas as atividades econômicas afetadas pelo choque de demanda de açúcar.

Observa-se também que o impacto do efeito renda, verificado pela diferença entre o total dos impactos (direto, indireto e induzido) do valor dos impactos direto e indireto, apresenta-se maior, quando o choque é simulado na região Norte-Nordeste do que quando o choque é dado no Centro-Sul. Pressupõe-se que o efeito renda maior no Norte-Nordeste sobre a produção das duas regiões ocorra porque o Norte-Nordeste é uma região relativamente mais pobre do que o Centro-Sul, respondendo, portanto, de maneira relativamente mais intensa a um aumento da renda.

Os resultados apresentaram o mesmo padrão quando verificados os impactos do aumento de demanda de álcool. Entretanto, os efeitos sobre o nível de produção na economia brasileira em função do aumento na demanda de álcool apresentaram-se menores em relação ao observado para o açúcar. Considerando os efeitos totais na produção (impacto direto, indireto e induzido pelo aumento de renda), o aumento de $\mathrm{R} \$$ 1 milhão demanda de álcool no Centro-Sul aumentou a produção do Norte-Nordeste em $\mathrm{R} \$$ 0,168 milhões e a produção da própria região em R \$ 2,254 milhões. Já o aumento de R 1 milhão na demanda de álcool do Norte-Nordeste aumentou a produção da própria região em R \$ 2,155 milhões e da região Centro-Sul em R \$ 695 mil.

\subsection{Impacto sobre o nível de emprego}

De forma semelhante ao que se observa para a produção, os resultados de choques derivados de incrementos nas exportações de açúcar e álcool, sobre o nível de emprego são, de maneira geral, mais expressivos quando provocados, a princípio, na região Norte-Nordeste.

A Tabela 3 mostra o impacto, quando o aumento de demanda pelo açúcar ocorre na região Centro-Sul e no Norte-Nordeste, sobre o número de empregos gerados no Norte-Nordeste e no Centro-Sul. 
Tabela 3. Variações nos níveis de emprego dos setores da economia do Norte-Nordeste (NNE) e do Centro-Sul (CS), resultantes do impacto direto, indireto e induzido pelo efeito renda, de aumento de $\mathrm{R} \$ 1$ milhão na demanda final de açúcar nestas regiões

\begin{tabular}{|c|c|c|c|c|}
\hline \multirow[b]{2}{*}{ Setores } & \multicolumn{2}{|c|}{$\begin{array}{c}\text { Impacto na economia } \\
\text { do NNE } \\
\end{array}$} & \multicolumn{2}{|c|}{$\begin{array}{c}\text { Impacto na economia } \\
\text { do CS } \\
\end{array}$} \\
\hline & $\begin{array}{l}\text { Aumento na } \\
\text { demanda de } \\
\text { açúcar no } \\
\text { NNE }\end{array}$ & $\begin{array}{l}\text { Aumento na } \\
\text { demanda de } \\
\text { açúcar no CS }\end{array}$ & $\begin{array}{l}\text { Aumento } \\
\text { na demanda } \\
\text { de açúcar no } \\
\text { NNE }\end{array}$ & $\begin{array}{l}\text { Aumento } \\
\text { na demanda } \\
\text { de açúcar } \\
\text { no CS }\end{array}$ \\
\hline 1 Cana-de-açúcar & 53,9 & 4,1 & 3,7 & 19,4 \\
\hline 2 Resto Agropecuária & 30,0 & 5,0 & 5,3 & 5,9 \\
\hline 3 Extrativa & 0,2 & 0,1 & 0,2 & 0,2 \\
\hline 4 Metalurgia & 0,3 & 0,1 & 0,5 & 0,5 \\
\hline 5 Mecânica & 0,4 & 0,1 & 0,6 & 0,7 \\
\hline $\begin{array}{l}\text { Material Elétrico e } \\
\text { Eletrônico }\end{array}$ & 0,1 & 0,0 & 0,1 & 0,1 \\
\hline 7 Material de Transporte & 0,0 & 0,0 & 0,3 & 0,1 \\
\hline $\begin{array}{l}\text { Madeira, Mobiliário, } \\
\text { Celulose, Papel e Gráfica }\end{array}$ & 1,3 & 0,3 & 1,1 & 1,0 \\
\hline 9 Álcool & 0,0 & 0,0 & 0,0 & 0,0 \\
\hline $\begin{array}{l}10 \text { Outros Elementos Quími- } \\
\text { cos não Petroquímicos }\end{array}$ & 0,0 & 0,0 & 0,0 & 0,0 \\
\hline 11 Refino do Petróleo & 0,0 & 0,0 & 0,1 & 0,1 \\
\hline $\begin{array}{l}\text { Produtos do Refino do } \\
\text { Petróleo }\end{array}$ & 0,4 & 0,1 & 0,6 & 0,5 \\
\hline $13 \begin{array}{l}\text { Têxtil, Vestuário e } \\
\text { Calçados }\end{array}$ & 3,4 & 0,7 & 2,9 & 3,7 \\
\hline 14 Fabricação de Açúcar & 15,0 & 0,0 & 0,1 & 10,4 \\
\hline $\begin{array}{l}\text { Outros Produtos } \\
\text { Alimentares }\end{array}$ & 1,9 & 0,2 & 0,7 & 0,8 \\
\hline 16 Indústrias Diversas & 0,4 & 0,1 & 0,5 & 0,5 \\
\hline 17 SIUP & 0,5 & 0,0 & 0,1 & 0,3 \\
\hline 18 Construção Civil & 0,4 & 0,0 & 0,1 & 0,4 \\
\hline $\begin{array}{l}\text { Serviços Prestados às } \\
\text { Famílias }\end{array}$ & 16,6 & 1,6 & 3,0 & 6,2 \\
\hline 20 Outros Serviços & 30,8 & 2,8 & 10,0 & 18,5 \\
\hline
\end{tabular}

Fonte: resultados de pesquisa. 
Observa-se ainda na Tabela 3, um impacto sobre o nível de emprego superior na região Norte-Nordeste em relação à região Centro-Sul, quando o impacto ocorre na própria região que recebeu o choque. Os maiores efeitos sobre o nível de emprego ocorreram nos setores: setor 1 - cana-de-açúcar (com a criação de 54 empregos no Norte-Nordeste e 19 empregos no Centro-Sul); setor 2 - restante agropecuária (30 empregos no Norte-Nordeste e 6 empregos no Centro-Sul); setor 14 - fabricação de açúcar (15 empregos no Norte-Nordeste e 10 empregos no Centro-Sul); setor 19 - serviços prestados às famílias (17 empregos no Norte-Nordeste e 6 empregos no Centro-Sul); e setor 20 - outros serviços (30 empregos no Norte-Nordeste e 18 empregos no Centro-Sul).

Considerando os efeitos inter-regionais de um aumento na demanda final de açúcar sobre o nível de emprego, os resultados também apresentaram um impacto maior quando o choque de demanda inicia-se na região Norte-Nordeste.

Os setores que apresentaram um aumento de mais de 2 empregos no Norte-Nordeste em função de um aumento na demanda no Centro-Sul foram os seguintes: setor 1 - cana-de-açúcar (criação de 4 novos empregos) e setor 2 - resto agropecuária (criando 5 novos empregos). Um aumento do número de empregos gerados no Centro-Sul mediante um aumento de demanda no Norte-Nordeste, foi observado nos seguintes setores: 1 - cana-de-açúcar (4 empregos adicionais); 2 - restante agropecuária (aumento de 5 novos empregos); 13 - têxtil, vestuário e calçados (aumento de 3 empregos); 19 - serviços prestados às famílias (criação de 3 postos de trabalho) e 20 - outros serviços (criando 20 empregos),

Na Tabela 4 tem-se o resultado do impacto do aumento na demanda de álcool sobre a geração de empregos nas duas regiões. Observa-se que o impacto do choque intra-regional foi maior no próprio setor de álcool e nos setores: 1 - cana-de-açúcar (impactos direto, indireto e induzido de 22 novos postos de emprego no Centro-Sul e 55 no Norte-Nordeste) e no setor 20 - outros serviços (impacto direto, indireto e induzido de 12 novos empregos no Centro-Sul e 19 empregos no Norte-Nordeste). 
Tabela 4. Variações nos níveis de emprego dos setores da economia do Norte-Nordeste (NNE) e do Centro-Sul (CS), resultantes do impacto direto, indireto e induzido pelo efeito renda, de aumento de $\mathrm{R} \$ 1$ milhão na demanda final de álcool nestas regiões

\begin{tabular}{|c|c|c|c|c|c|}
\hline & \multirow[b]{2}{*}{ Setores } & \multicolumn{2}{|c|}{$\begin{array}{c}\text { Impacto na economia } \\
\text { do NNE }\end{array}$} & \multicolumn{2}{|c|}{$\begin{array}{c}\text { Impacto na economia } \\
\text { do CS }\end{array}$} \\
\hline & & $\begin{array}{l}\text { Aumento na } \\
\text { demanda de } \\
\text { açúcar no } \\
\text { NNE }\end{array}$ & $\begin{array}{l}\text { Aumento na } \\
\text { demanda de } \\
\text { açúcar no CS }\end{array}$ & $\begin{array}{l}\text { Aumento na } \\
\text { demanda de } \\
\text { açúcar no } \\
\text { NNE }\end{array}$ & $\begin{array}{l}\text { Aumento na } \\
\text { demanda de } \\
\text { açúcar no CS }\end{array}$ \\
\hline 1 & Cana-de-açúcar & 54,5 & 3,0 & 3,5 & 21,8 \\
\hline 2 & Resto Agropecuária & 19,4 & 3,8 & 3,4 & 4,0 \\
\hline 3 & Extrativa & 0,1 & 0,1 & 0,2 & 0,1 \\
\hline 4 & Metalurgia & 0,1 & 0,1 & 0,3 & 0,2 \\
\hline 5 & Mecânica & 0,2 & 0,0 & 0,3 & 0,4 \\
\hline 6 & $\begin{array}{l}\text { Material Elétrico e } \\
\text { Eletrônico }\end{array}$ & 0,0 & 0,0 & 0,1 & 0,1 \\
\hline 7 & Material de Transporte & 0,0 & 0,0 & 0,2 & 0,1 \\
\hline 8 & $\begin{array}{l}\text { Madeira, Mobiliário, } \\
\text { Celulose, Papel e } \\
\text { Gráfica }\end{array}$ & 0,6 & 0,2 & 0,6 & 0,5 \\
\hline 9 & Álcool & 3,4 & 0,0 & 0,0 & 3,3 \\
\hline 10 & $\begin{array}{l}\text { Outros Elementos } \\
\text { Químicos não } \\
\text { Petroquímicos }\end{array}$ & 0,1 & 0,0 & 0,1 & 0,1 \\
\hline 11 & Refino do Petróleo & 0,0 & 0,0 & 0,0 & 0,0 \\
\hline 12 & $\begin{array}{l}\text { Produtos do Refino } \\
\text { do Petróleo }\end{array}$ & 0,3 & 0,1 & 0,4 & 0,4 \\
\hline 13 & $\begin{array}{l}\text { Têxtil, Vestuário e } \\
\text { Calçados }\end{array}$ & 1,1 & 0,2 & 1,1 & 0,9 \\
\hline 14 & Fabricação de Açúcar & 0,7 & 0,1 & 0,1 & 0,5 \\
\hline 15 & $\begin{array}{l}\text { Outros Produtos } \\
\text { Alimentares }\end{array}$ & 1,2 & 0,2 & 0,4 & 0,5 \\
\hline 16 & Indústrias Diversas & 0,2 & 0,1 & 0,3 & 0,2 \\
\hline 17 & SIUP & 0,4 & 0,1 & 0,1 & 0,3 \\
\hline 18 & Construção Civil & 0,2 & 0,0 & 0,1 & 0,2 \\
\hline 19 & $\begin{array}{l}\text { Serviços Prestados } \\
\text { às Famílias }\end{array}$ & 10,3 & 1,2 & 1,8 & 3,9 \\
\hline 20 & Outros Serviços & 18,8 & 2,3 & 6,3 & 11,6 \\
\hline
\end{tabular}

Fonte: resultados de pesquisa. 
Os valores dos impactos cruzados do aumento de demanda por álcool de uma região sobre o nível de emprego da outra região são descritos nas quarta e quinta colunas da Tabela 4. Da mesma maneira como ocorreu como o aumento de demanda de açúcar, e também com os impactos sobre o nível de produção, o efeito inter-regional do choque de demanda, sobre o álcool no Norte-Nordeste, causou um aumento maior no número de empregos no Centro-Sul, que o inverso.

Os setores que produziram maior número de empregos em função de um choque de demanda de álcool na outra região foram: setor 1 - cana-de-açúcar (3,5 empregos no Centro-Sul e 3 empregos no NorteNordeste); setor 2 - resto agropecuária (3,3 empregos no Centro-Sul 4 empregos no Norte-Nordeste); setor 19 - serviços prestados às famílias (1,8 empregos no Centro-Sul e 1,2 empregos no Norte-Nordeste) e setor 20 - outros serviços (6,3 empregos no Centro-Sul e 2,3 empregos no Norte-Nordeste).

Verificou-se que em se tratando do nível de produção, o setor mais impactado sempre foi o setor que sofreu o choque de demanda (de açúcar ou de álcool), seguido pelo setor de cana-de-açúcar. O mesmo não é observado quando se considera o impacto sobre o nível de emprego. Os resultados mostraram que o setor da cana-de-açúcar gerou um número de empregos maior do que o setor que recebeu o choque. Além disso, outros que também foram indiretamente afetados, também geraram um número de empregos superior ao setor que sofreu o choque (por exemplo, resto da agropecuária, serviços prestados à família e outros serviços). Isto pode ser explicado pelo fato desses setores demandarem maior volume de empregos do que as atividades de produção de açúcar e de álcool.

A Figura 2 sintetiza os resultados obtidos sobre o aumento no número de empregos gerados em toda a economia em função do aumento de demanda de açúcar e de álcool nas duas regiões.

Inicialmente, observa-se que para o aumento no valor da produção da economia, o número de empregos gerados por um choque na demanda por açúcar foi maior do que o impacto sobre a demanda por álcool. O número de empregos gerados em função do aumento de renda é representado na Figura 2, pela diferença entre as barras referentes ao número de empregos gerados pelos efeitos direto, indireto, e induzido, e as barras referentes ao número de empregos diretos e indiretos. Essa 
diferença mostra o maior poder de geração de empregos quando o choque de demanda ocorre na região Norte-Nordeste.

Figura 2 - Impactos sobre o número de empregos gerados anualmente na economia das regiões Centro-Sul e Norte-Nordeste do Brasil, em relação ao aumento de demanda final de açúcar e de álcool no valor de R 1 milhão, nas regiões Centro-Sul e Norte-Nordeste

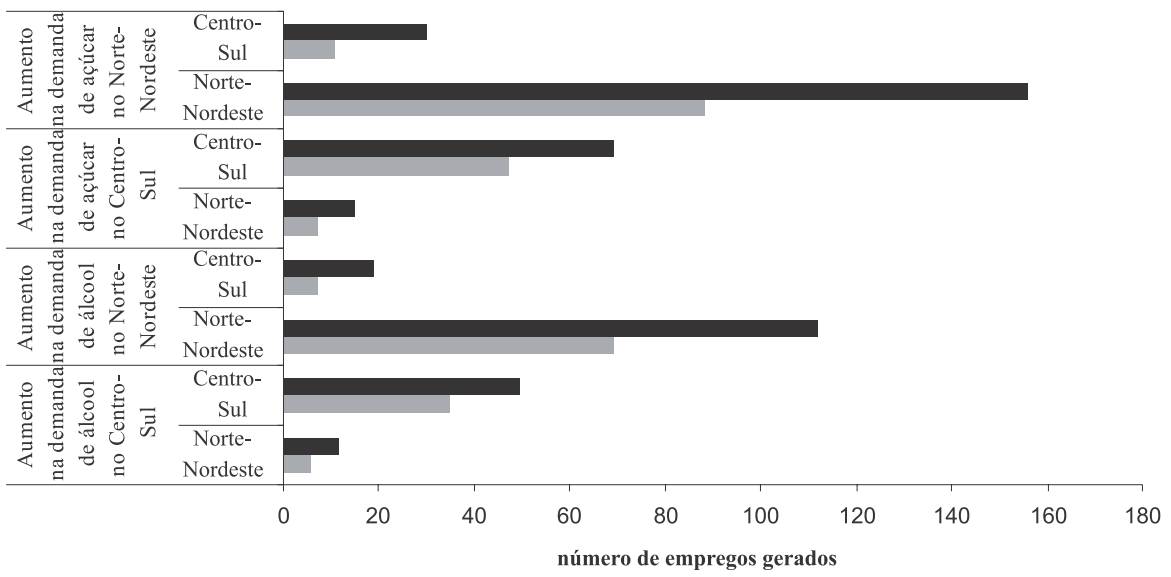

direto+indireto $\square$ direto+indireto+induzido

Fonte: resultados de pesquisa.

Nota: o efeito induzido corresponde ao aumento da produção em função do aumento do efeito renda das famílias.

Os impactos totais (direto, indireto e induzido) de um aumento na demanda de R\$ 1 milhão pelo açúcar do Centro-Sul produziram um aumento de 69 empregos/ano na própria região e 15 empregos/ano no Norte-Nordeste. Esse mesmo choque no Norte-Nordeste aumentou em 156 empregos/ano naquela região e 30 empregos/ano no Centro-Sul. Numa proporção um pouco menor, verificou-se que o aumento de demanda de R\$ 1 milhão de álcool no Centro-Sul aumentou o número de empregos em 49 empregos ao ano na mesma região e em 12 empregos ao ano na outra região. Quando o choque de demanda de álcool foi simulado para o Norte-Nordeste, o aumento no número de empregos foi de 112 empregos/ano no Norte-Nordeste e 19 empregos/ano no Centro-Sul.

É importante ressaltar, ainda, que embora o número de empregos criados mostre-se relativamente baixo, em termos absolutos, deve-se 
observar que esses referem-se a um choque de $\mathrm{R} \$ 1$ milhão. Um impacto dessa magnitude corresponde a menos que $0,05 \%$ das exportações de açúcar do Brasil, considerando a média anual do valor total de açúcar exportado nos últimos sete anos.

Dessa forma, os resultados devem ser interpretados como uma indicação da sensibilidade de cada região frente a um possível aumento de demanda. Na realidade, considerando especificamente o mercado de açúcar, espera-se que ocorra um aumento de demanda pelas exportações brasileiras, em função de reduções em barreiras protecionistas no mercado internacional do produto, superior a $\mathrm{R} \$ 1$ milhão, embora a sua magnitude exata, em valores, seja difícil de precisar. Em termos de volume, estudo realizado por Borrell \& Pearce (1999) estimou aumentos de exportação de açúcar brasileiro de mais de 5 milhões de toneladas para 2008, utilizando um modelo para o mercado mundial de adoçantes, conhecido como "Global Sweetener Market" (GSM), e tomando como base o ano de 2000. Sheales et al. (1999) estimaram um incremento dessas mesmas exportações em cerca de 2,2 milhões de toneladas para 2005, usando o modelo conhecido como SUGABARE, para um horizonte de tempo de 1999 a 2005. Considerando que o preço da tonelada de açúcar corresponde a valores superiores a R \$ 100,00/tonelada, os choques estimados por esses trabalhos, quando originados na economia brasileira, seriam muito superiores ao $\mathrm{R} \$ 1$ milhão considerado para a análise conduzida no presente trabalho.

\section{Conclusão}

As relações apresentadas na matriz insumo-produto inter-regional utilizada neste trabalho sugerem que choques provenientes de incrementos na demanda final de açúcar e de álcool podem ter um impacto mais expressivo para a economia brasileira como um todo, quando ocorrem no Norte-Nordeste, comparado ao originado no Centro-Sul. A maior resposta relativa observada quando o impacto é sobre a região NNE, sugere que as distorções prevalecentes no mercado internacional causam maior prejuízo em termos de emprego e produto agregado para as regiões produtoras menos competitivas do país, onde o setor sucroalcooleiro assume uma importância determinante para a economia da 
região. Esse é um argumento importante a ser destacado nas negociações de redução de medidas protecionistas, particularmente quando as contrapartes são países ricos, como a UE e os Estados Unidos, que têm respaldado a defesa ao apoio mantido para o setor açucareiro nacional, em um aspecto social global. A UE argumenta que os países pobres da ACP seriam bastante prejudicados com uma mudança na política adotada, enquanto os EUA argumentam que sua política é benéfica para os países pobres da América Central. No caso brasileiro, o estudo mostrou que a região mais prejudicada é uma das mais pobres do país, onde prevalecem sérios problemas sociais.

Verificou-se ainda, que os choques na economia provocados por um aumento de demanda externa pelo açúcar brasileiro foram maiores que os derivados de incrementos na demanda externa pelo álcool brasileiro. Temse, portanto, uma indicação de que abertura de mercados ao etanol - o que vem se tornando uma opção cada vez mais interessante e conveniente aos países desenvolvidos que acumulam uma grande dívida ambiental -, como uma compensação para a intransigência quanto a qualquer redução nas medidas protecionistas mantidas para o açúcar, devem ser criteriosamente avaliadas, considerando-se não apenas equivalentes técnicos entre os produtos, como também o maior impacto associado a um incremento relativo pela demanda de açúcar, dada a estrutura produtiva do país.

Esses resultados têm o propósito de fornecer dados que possam subsidiar decisões governamentais a respeito de se incentivar ou não uma região produtora em detrimento da outra, ou um produto em detrimento a outro, uma vez que os produtos são concorrentes na sua produção.

\section{Referências bibliográficas}

BORRELL, B.; PEARCE, D. Sugar: the taste test of trade liberalisation. Canberra: Centre for International Economics - CIE, Sep. 1999. (Reports) http://www.thecie.com.au/publicat.htm (02 May 2003)

MILLER, R.E.; BLAIR, P.D. Input-output analysis: foundations and extensions. Englewood Cliffs, New Jersey: Prentice-Hall, Inc., 1985. 464 p.

NAJBERG, S.; IKEDA, M. Modelo de geração de emprego: metodologia e resultados. Rio de Janeiro: IPEA, 1999. 61p. (Textos para Discussão, 72) 
SHEALES, T.; GORDON, S.; HAFI, A.; TOYNE, C. Sugar: international policies affecting market expansion, Canberra: ABARE Research Report 99.14, 1999. http://www.dfat.gov.au/trade/negotiations/ministerial/ sugar_9914.pdf (10 out. 2002)

\section{ANEXO 1}

Quadro 1 - Definição dos setores que compõem a matriz insumo-produto utilizada neste trabalho

\begin{tabular}{|c|c|c|}
\hline $\begin{array}{l}\mathrm{N}^{\circ} \text { do } \\
\text { setor }\end{array}$ & Nome do setor da matriz utilizada & $\begin{array}{l}\text { Setores agregados em relação a } \\
\text { matriz divulgada pelo IBGE }\end{array}$ \\
\hline 1 & Cana-de-açúcar & \multirow{2}{*}{ Agropecuária } \\
\hline 2 & Resto agropecuária & \\
\hline \multirow{2}{*}{3} & \multirow{2}{*}{ Extrativa } & Extrativa mineral \\
\hline & & Extração de petróleo e gás \\
\hline \multirow{3}{*}{4} & \multirow{3}{*}{ Metalurgia } & Siderurgia \\
\hline & & Metalurgia não-ferrosos \\
\hline & & Outros metalúrgicos \\
\hline 5 & Máquinas e tratores & \\
\hline \multirow{2}{*}{6} & \multirow{2}{*}{ Material elétrico e eletrônico } & Material elétrico \\
\hline & & Equipamentos eletrônicos \\
\hline \multirow{2}{*}{7} & \multirow{2}{*}{ Material de transporte } & Automóveis, caminhões e ônibus \\
\hline & & Outros veículos e peças \\
\hline \multirow{2}{*}{8} & \multirow{2}{*}{$\begin{array}{l}\text { Madeira, mobiliário, celulose, papel e } \\
\text { gráfica }\end{array}$} & Madeira e mobiliário \\
\hline & & Papel e gráfica \\
\hline 9 & Álcool & \\
\hline 10 & $\begin{array}{l}\text { Outros elementos químicos não } \\
\text { petroquímicos }\end{array}$ & Elementos químicos \\
\hline 11 & Refino do petróleo & \\
\hline \multirow{3}{*}{12} & \multirow{3}{*}{ Produtos do refino do petróleo } & Químicos diversos \\
\hline & & Farmacêutica e de perfumaria \\
\hline & & Artigos de plástico \\
\hline \multirow{3}{*}{13} & \multirow{3}{*}{ Têxtil, vestuário e calçados } & Indústria têxtil \\
\hline & & Artigos de vestuário \\
\hline & & Fabricação de calçados \\
\hline 14 & Fabricação de açúcar & \\
\hline
\end{tabular}




\begin{tabular}{|c|c|c|}
\hline \multirow{6}{*}{15} & \multirow{6}{*}{ Outros produtos alimentares } & Indústria do café \\
\hline & & Benef. prod. vegetais \\
\hline & & Abate de animais \\
\hline & & Indústria de laticínios \\
\hline & & Fab. óleos vegetais \\
\hline & & Outros prod. alimentares \\
\hline \multirow{3}{*}{16} & \multirow{3}{*}{ Indústrias diversas } & Minerais não metálicos \\
\hline & & Indústria da borracha \\
\hline & & Indústrias diversas \\
\hline 17 & \multicolumn{2}{|c|}{ Serviços industriais de utilidade pública (SIUP) } \\
\hline 18 & \multicolumn{2}{|c|}{ Construção civil } \\
\hline 19 & \multicolumn{2}{|l|}{ Serviços prestados às famílias } \\
\hline
\end{tabular}

